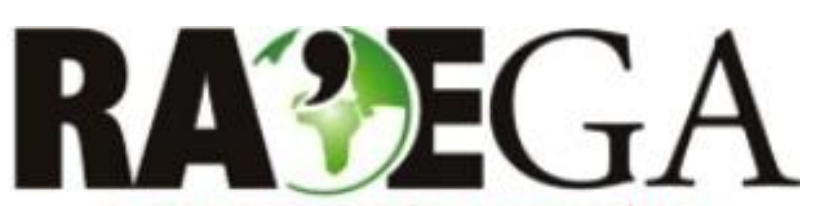

O ESPACYO GEOGRÁFICO EM ANÁLISE

\title{
CONTRIBUIÇÃO AOS ESTUDOS DA PRECIPITAÇÃO NO ESTADO DO PARANÁ: A OSCILAÇÃO DECADAL DO PACÍFICO - ODP ${ }^{1}$
}

\section{CONTRIBUTION TO PRECIPITATION STUDIES IN PARANÁ STATE: THE PACIFIC DECADAL OSCILLATION - PDO}

\author{
Lindberg Nascimento Júnior \\ Programa de Pós Graduação em Geografia \\ Universidade Estadual Paulista \\ São Paulo, SP, Brasil \\ e-mail: juniohr@gmail.com \\ João Lima Sant'Anna Neto \\ Programa de Pós Graduação em Geografia \\ Universidade Estadual Paulista \\ São Paulo, SP, Brasil \\ e-mail: joaolima@fct.unesp.br
}

Recebido em: 08/07/2015

Aceito em: 20/01/2016

\begin{abstract}
Resumo
A Oscilação Decadal do Pacífico - ODP - tem sido discutida como a teleconexão de baixa frequência mais recorrente do Oceano Pacífico. A oscilação é caracterizada por meio das temperaturas da superfície do mar e pela temporalidade de atuação na escala de 20 a 30 anos. No Brasil, associações entre ODP nas dinâmicas climáticas regionais e locais são verificadas principalmente na variabilidade pluviométrica. No Paraná, estudos que associaram a oscilação à dinâmica pluviométrica e/ou climática foram obtidos de forma indireta. Nesse contexto, o objetivo do trabalho é apresentar as características por meio de associações e correlações espaciais e temporais obtidas por testes estatísticos para a precipitação no Estado. O intuito é contribuir com os estudos sobre a gênese das chuvas na região, considerando a variabilidade pluviométrica em escala decadal, e destacando a ODP como um fenômeno que auxilia na produção das chuvas no Estado. Foram utilizadas séries históricas de 1976 a 2011: a) com dados mensais de chuva e número de

\footnotetext{
${ }^{1}$ Parte dos resultados da dissertação de mestrado em geografia defendida em 2013, intitulada "As chuvas no Paraná: variabilidade, teleconexões e impactos de eventos extremos", e financiada pela Fundação de Amparo à Pesquisa do Estado de São Paulo - FAPESP.
} 
dias com chuva, agrupados em escalas trimestrais, sazonais e anuais; e b) com índices anuais padronizados da ODP. A caracterização foi processada pela associação em função da similaridade temporal da ODP e das chuvas no Paraná e as correlações foram obtidas pelo coeficiente de correlação linear de Pearson. Em geral, a participação da ODP se mostrou com sinal fraco para chuvas, numa relação de $11 \%$ a $20 \%$, considerando o coeficiente de determinação $\left(\mathrm{r}^{2}\right)$. Para os números de dias com chuva a correlação foi de 17 a $46 \%$, sugerindo uma relação com sinal moderado-fraco. Os resultados corroboram para o melhor entendimento das gêneses das chuvas em regiões de clima tropical, especialmente para o Paraná, e aponta abordagens interpretativas dos impactos regionais e locais de teleconexões climáticas de baixa frequência.

Palavras chave: Precipitação; Variabilidade; Oscilação Decadal do Pacífico; Impactos; Estado do Paraná.

\section{Abstract}

The major teleconnections of low frequency observed into Pacific Ocean, the Pacific Decadal Oscillation - PDO has been discussed as recurrent in the decadal temporality (20 and 30 years). The oscillation is characterized by surface sea temperatures, and it shows associations between regional climate dynamics, mostly in the rainfall variability. The studies that combined oscillation and rainfall dynamics in Paraná State (localizated in South of Brasil) were indirectly obtained. In this context, the aim is to present the PDO'characteristics, associations and spatial and temporal correlations of rainfall in the state, obtained by statistical tests. The objetctive is contribute to genesis and production rains studies, considering the decadal raifall variability, and highlighting the PDO like one pattern teleconnection. We used months data series from 1976 to 2011, with rainfall data and number of rain days grouped into quarterly, seasonal and annual scales. The PDO was representend by annual index. The characterization was processed by the association through the temporal similarity. The correlations were obtained by linear correlation coefficient of Pearson. In general the PDO influence was 11 to $20 \%$, and for the numbers of rain days was 17 to $46 \%$, it is suggesting a weak and weakmoderate correlations. This results supports the understanding of rainfall in tropical areas, and also points interpretative approaches to regional and local impacts of teleconnections influence in variability.

Key Words: Precipitation; Variability; Pacific Decadal Oscillation; Impacts; Paraná State

\section{INTRODUÇÃO}


Das principais configurações de teleconexões que afetam a variabilidade climática global e, em particular da América do Sul, estão os fenômenos El Niño Oscilação Sul - ENOS e a Oscilação Decadal do Pacífico - ODP (CAVALCANTI e AMBRIZZI, 2009; GRIMM, 2009a).

O ENOS é o principal modulador da variabilidade interanual e a ODP tem sido considerada como um importante modo de variabilidade de baixa e baixíssima frequência em escalas decadal e multidecadal (CAVALCANTI e OLIVEIRA, 1996; KAYANO e ANDREOLI, 2006; 2009; CAVALCANTI e AMBRIZZI, 2009; GRIMM, 2009a).

Para o território brasileiro, esses padrões climáticos são associados principalmente à precipitação. Os ENOS indicam marcada variação interanual e intersazonal, sendo o principal modulador das chuvas nessas escalas (GRIMM et al., 1997; GRIMM, 2009a; 2009b). Os padrões ODP são associados à explicação de que determinadas décadas se apresentam mais ou menos chuvosas do que outras (CAVALCANTI e AMBRIZZI, 2009; KAYANO e ANDREOLI, 2006; 2009)

No Estado do Paraná, devido ao caráter de clima tropical e transicional (regiões de confronto dos sistemas tropicais e extratropicais), os sinais dos padrões ENOS são discretos e, quando presentes, são destacados por variações com valores extremos, por apresentarem maior similaridade temporal, como observado por Nery et al. (1996; 1997), Grimm et al. (1997), Baldo (2006), Souza (2006), Parizotto e Nery (2008) e Grimm (2004; 2009a; 2009b).

Os estudos que associaram a ODP à dinâmica pluviométrica e/ou climática no Estado do Paraná foram obtidos de forma indireta, especificamente em Nogarolli $(2007 ; 2010)$.

Nesse contexto, o objetivo do artigo é apresentar as associações e correlações espaciais e temporais da ODP na precipitação no Estado do Paraná através de análise estatística e geoestatistica.

O intuito é oferecer uma contribuição aos estudos sobre a gênese das chuvas na região, considerando a variabilidade pluviométrica decadal e 
multidecadal destacando a ODP como um fenômeno que auxilia na produção das chuvas no Estado nessas escalas temporais.

Para tanto, são apresentados os mecanismos genéticos das chuvas no Paraná e as principais características do fenômeno. Expõem-se os critérios técnicos e os procedimentos para tratamento dos dados, que formaram a base para as correlações temporais e espaciais e detecção da influência da oscilação. A discussão dos resultados é apresentada na quarta parte, destacando-se a significância estatística dos sinais da ODP na variabilidade pluviométrica nos postos utilizados, nos períodos observados e suas configurações espaciais.

\subsection{As chuvas no Paraná: gênese e distribuição espaço temporal}

De forma geral, a variabilidade pluviométrica no Paraná tem sido discutida e estudada de forma sistemática e bastante significativa ao longo das últimas décadas. Os trabalhos mais antigos e clássicos, como os elaborados por Maack (1981), Nimer (1989), Monteiro (1968) e Troppmair (1990), até os mais recentes, de Mendonça (2000), Mendonça e Danni-Oliveira (2007) e Grimm (2009a; 2009b), evidenciam esse fato.

A gênese das chuvas no Estado do Paraná associa-se à sua posição meridional em relação ao país, apresentando um clima e uma variabilidade pluviométrica basicamente determinados pela intensidade da Alta Subtropical do Atlântico, e das massas de ar tropicais e polares (vindas da Amazônia e do Sul) (NIMER; 1989; MENDONÇA, 2000; GRIMM, 2009a). São quatro massas de ar que atuam na região: a massa Equatorial Continental, a massa Tropical Continental, a massa Tropical Atlântica e a massa Polar Atlântica (NIMER, 1989).

As massas tropicais são predominantes no verão quando formam correntes de orientação de norte e nordeste, com sucessivos avanços e recuos acompanhados de instabilidade pré e pós-frontais. As correntes de oeste predominam nos meses de transição, principalmente no outono, formando a linha de instabilidade tropical, originando chuvas convectivas (TROPPMAIR, 1990).

R. Ra'e Ga - Curitiba, v. 35, p 314. - 343 , Dez/2015 
A Frente Polar Atlântica é o principal sistema produtor de chuva, e quando não é, está associado a dinâmica e a configurações de linhas de instabilidade e chuvas convectivas. Estas por sua vez, se associam aos ciclones extratropicais e aos vórtices ciclônicos em altos níveis (MONTEIRO, 1968; MENDONÇA, 2000; MENDONÇA e DANNI-OLIVEIRA, 2007).

A atuação dinâmica e cíclica desses sistemas é enriquecida pelas interações com os fatores estáticos - compartimentos geomorfológicos e relevo, que orientam o direcionamento habitual das chuvas e das massas de ar (NIMER; 1989; MENDONÇA, 2000; GRIMM, 2009a).

A distribuição espacial da precipitação é também um elemento importante que auxilia o entendimento desse contexto climático. Além de evidenciar as principais diferenciações pluviométricas no Estado.

Sobre esse aspecto, as propostas de regionalização da distribuição das chuvas no estado elaboradas por Maack (1981), Nery et al. (1997), IAPAR (2000) e Nogarolli (2007; 2010) (Figura 1) mostram que, mesmo sob diferentes técnicas de observação, séries históricas distintas e objetivos técnicocientíficos específicos, a variabilidade espacial ocorre da seguinte maneira:

1) o setor norte e a região do planalto de Curitiba apresentam média anual entre 1200 a $1600 \mathrm{~mm}$, os menores valores no Estado;

2) maior parte das regiões centro e sul, o norte da região sudoeste e a serra do Mar e toda a região oeste possuem valores médios anuais entre 1600 a $2000 \mathrm{~mm}$;

3) as maiores médias pluviométricas observadas são encontradas no litoral e no sul da região sudoeste;

4) no sudoeste do Terceiro Planalto, onde as altitudes não ultrapassam $900 \mathrm{~m}$, e também onde se localiza a cadeia de serra com altitudes entre 900 a 1200m, os índices pluviométricos são maiores do que nas demais áreas continentais do Estado;

5) os ventos alísios agem na distribuição, trazendo a umidade marítima para a faixa leste e exercem enorme influência no litoral, fazendo com que esse setor apresente os maiores índices pluviométricos de todo o Estado, se distinguido de todos os demais. 


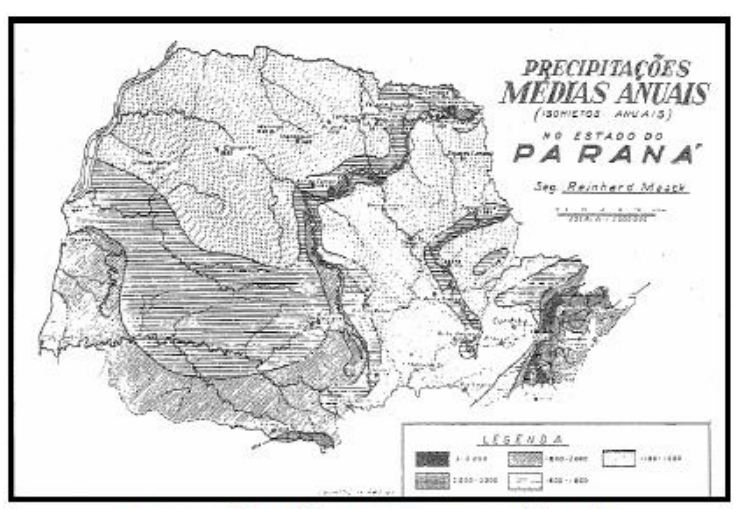

Precipitações Médias Anuais por Maack (1981)

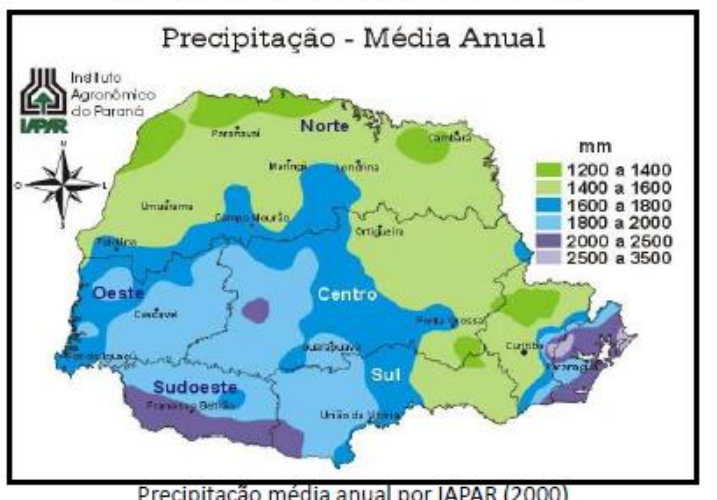

Precipitação média anual por IAPAR (2000)

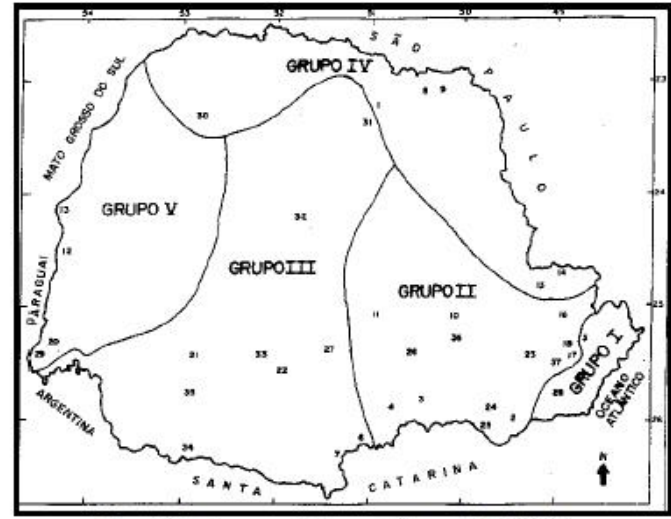

Precipitação acumulada por Nery et al. (1997)

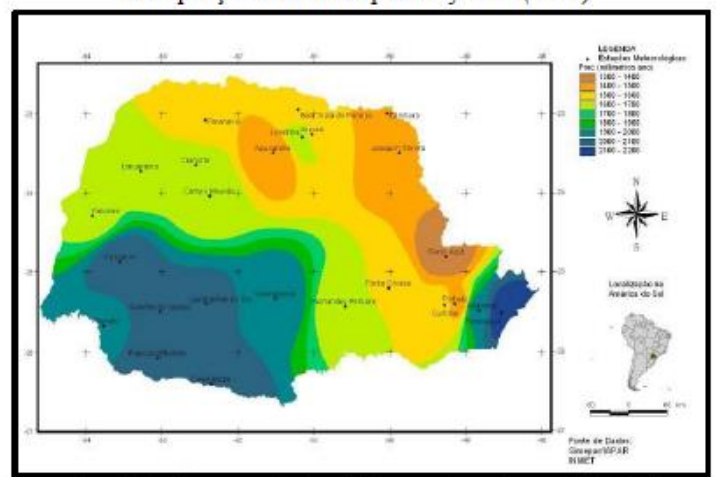

Precipitação acumulada média anual por Nogarolli (2007)

Figura 1 - Regionalizações da precipitação no Paraná, segundo Maack (1981), Nery et al. (1997), IAPAR (2000) e Nogarolli (2007). Org: Nascimento Jr e Sant'Anna Neto.

No que tange os estudos que associam a variabilidade das chuvas no espaço e no tempo, Grimm (2009a) indica que o trimestre chuvoso apresenta uma variabilidade de precipitação unimodal e bimodal, com um máximo na estação chuvosa.

A primeira característica - o modo unimodal de variabilidade, indica a configuração de regime subtropical de monções de verão e de transição climática. Nesse caso, no nordeste do Estado, as monções de verão apresentam máximo de precipitação no trimestre de dez/jan/fev, ou jan/fev/mar. Enquanto no oeste, a maior precipitação ocorre na primavera e, "[...] o pico da estação chuvosa muda do verão para o início da primavera, e então para o final do inverno, por meio de uma descontinuidade de fase" (GRIMM, 2009a, 273), apresentando a variabilidade bimodal. 
Essa característica expressa uma sazonalidade marcada por dois regimes (períodos chuvosos e menos chuvosos) em diversas regiões do Estado. Destacam-se entre eles os regimes: a) dos setores ao norte com as máximas de precipitação durante o verão, e o mês de janeiro com as médias pluviométricas mais elevadas; e, b) dos setores sul e litorâneo, onde a precipitação é uniforme e homogeneamente distribuídas ao longo do ano (NERY et al., 1996; IAPAR, 2000).

Regiões homogêneas quanto à variabilidade sazonal e intrasazonal foram observadas por Freitas (1998), Souza (2006), Pereira et al. (2008, p. 10), Roseghini et al. (2010), em que caracterizam quatro regiões pluviométricas, com datas distintas de início e fim da estação chuvosa. Na área ao norte verifica-se a ocorrência de uma estação seca (menos chuvosa) e com a ocorrência de veranicos no inverno, que diminui em direção aos setores sul do Estado.

Com base nesses conhecimentos e observações, é importante determinar qual a participação das teleconexões de baixa frequência, como a Oscilação Decadal do Pacífico - ODP nas chuvas no Paraná.

\subsection{Oscilação Decadal do Pacífico: características observacionais, hipóteses explicativas e repercussões associadas}

O padrão mais recorrente das temperaturas da superfície dos mares do oceano Pacífico na escala de décadas é a ODP. A variabilidade dessa oscilação é de 20 a 30 anos, portanto, é um modo de variabilidade de baixa ou baixíssima frequência (MANTUA et al., 1997; MANTUA e HARE, 2002; KAYANO e ANDREOLI, 2009).

A ODP tem sido comumente representada por pelo menos dois índices: a) índice mensal do NCDC - National Climatic Data Center- USA e; b) o índice mensal de Mantua e Hare (2002). O Índice da ODP (IODP) produzido por Mantua et al. (1997) e Mantua e Hare (2002), que tem sido derivado da 
primeira componente principal das anomalias das TSMs no Pacífico Norte ${ }^{2}$, entre as latitudes $20^{\circ} \mathrm{N}$ e $90^{\circ} \mathrm{N}$ (Polo), com a retirada da tendência climática (figura 2).

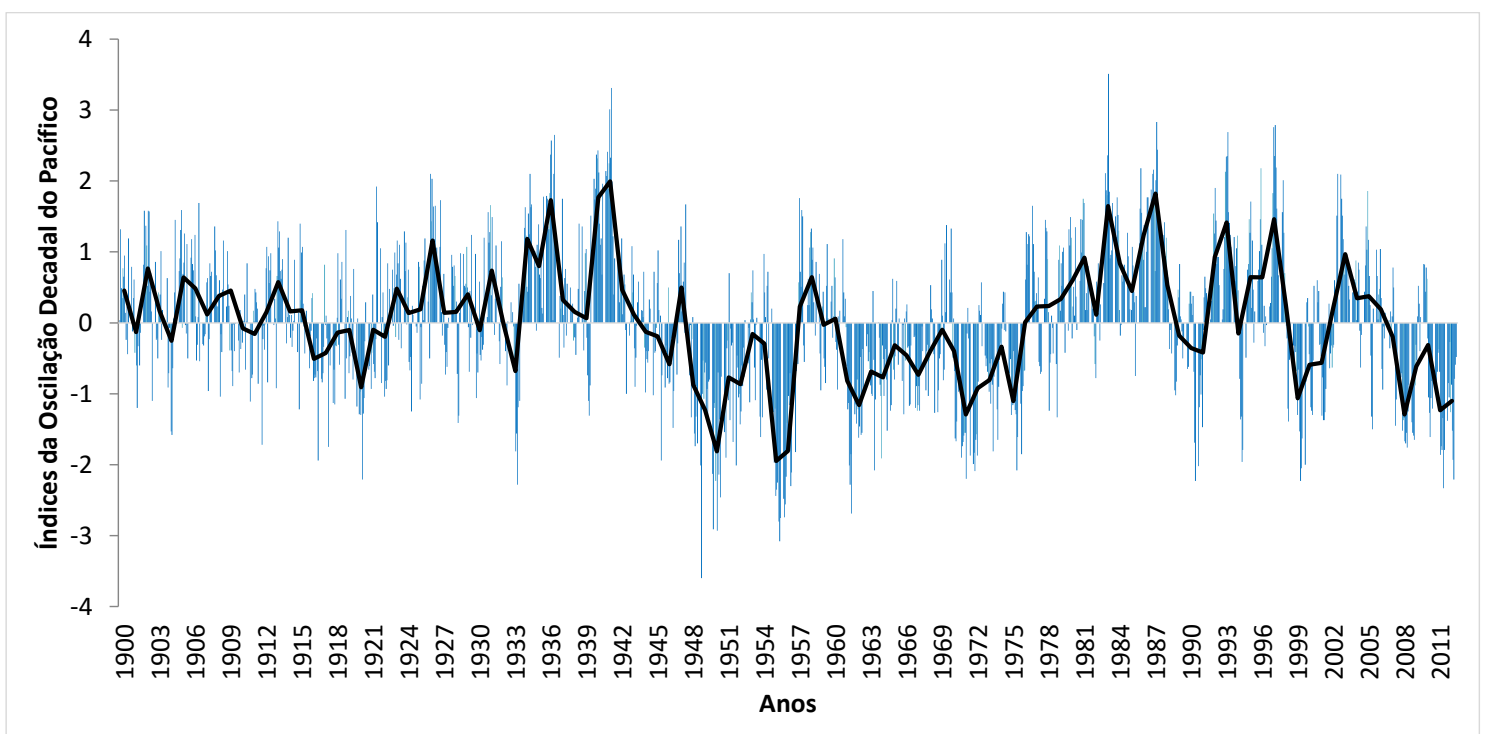

Figura 2 - Variabilidades dos IODP mensal (barras azul) e anual (linha preta) Fonte: Mantua e Hare (2002).

Os IODPs mensais apresentam variações bem marcadas, nas quais as ocorrências de fases frias são denominadas de ODP Negativa (padrão observado entre 1947 a 1975, com predominância de índices negativos) e fases quentes, chamadas de ODP Positiva (entre 1976 a 1997, com predominância de valores positivos dos índices).

Essas fases representam, respectivamente, a caracterização do conjunto de anomalias de TSM com configurações superficiais do Oceano Pacífico em duas fases distintas - Quente e Fria, em que são observadas anomalias positivas (negativas) no Pacífico Tropical e, negativas (positivas) no Pacífico Extratropical, como é observado na Figura 3.

\footnotetext{
$2 \mathrm{Na}$ análise de Componentes Principais ou Principal Component Analysis (PCA) 0 procedimento matemático utiliza uma transformação ortogonal para converter um conjunto de variáveis correlacionadas a outro conjunto de variáveis não correlacionadas. Chamadas componentes principais, as variáveis são ranqueadas, e a primeira é a que mostra maior variância possível se comparada aos demais componentes observados (SMITH, 2002).
} 


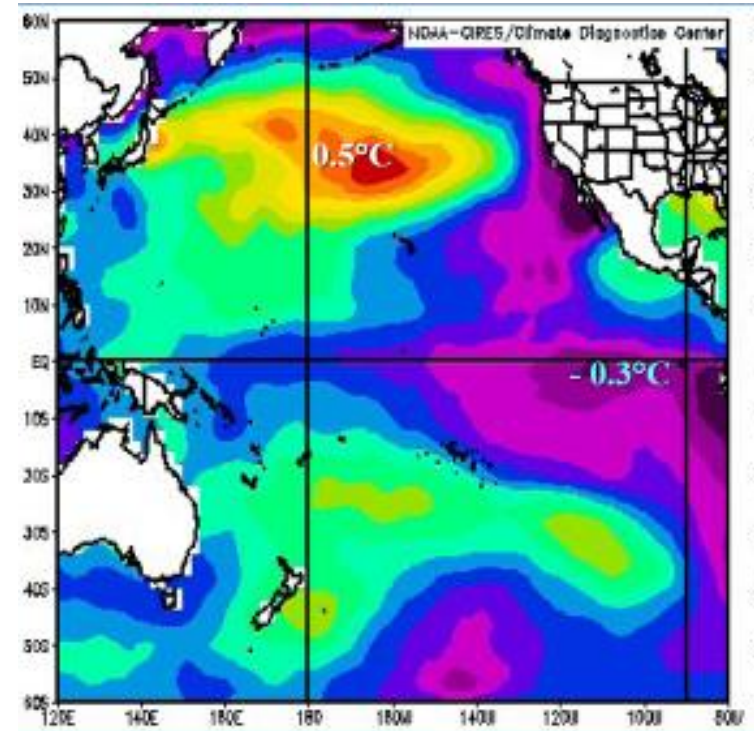

Fase Fria (1947 a 1976)

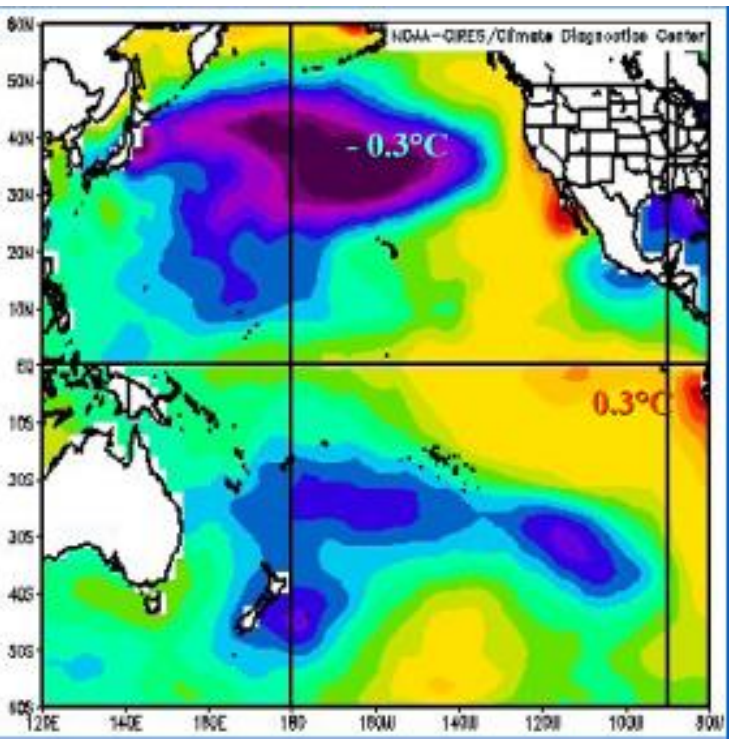

Fase Quente (1977 a 1998)

Figura 3 - Configuração das TSMs do Oceano Pacífico em fases distintas da ODP. Fonte: MOLION (2005).

Foi a partir da década de 1990, com base em pesquisas sobre a variação decadal das TSMs correlacionadas com as secas e chuvas intensas (e inundações) no verão chinês, que Wang (1995) e Wang et al. (1981) utilizaram pela primeira vez o termo Pacific Decadal Oscillation.

Outros termos foram cunhados para denominar a oscilação, como em Liu et al. (2002) que se referiram como Oscilação Bidecadal; Minobe (2000) sugeriu o nome Oscilação Pentadecadal (devido à observação do modo de variabilidade de cinquenta a setenta anos).

Cabe ressaltar que até a década de 1990, os estudos de variações decadais ou decenais eram considerados a partir de um processo lento (de baixa frequência) e a evidência de temporalidade em escala interdecadal (REBELLO, 2005).

Nesse contexto, Wang et al. (1981) observou relações entre secas e chuvas intensas (inundações) no verão chinês e a caracterização de uma oscilação de 20 e 30 anos; Beamish e Boullion (1993) descreveram os regimes de alternância da produção do salmão no Canadá, no Japão, Estados Unidos e Rússia; e logo mais tarde, Hare e Francis (1995) designavam o termo Pacific Decadal Oscillation - PDO (ou Oscilação Decadal do Pacífico) para a R. Ra'e Ga - Curitiba, v. 35, p 314. - 343 , Dez/2015 
característica de conexões entre a produção de salmão e as condições climáticas no Oceano Pacífico.

Estudos mais recentes sobre a característica decadal e interdecadal das TSMs no Oceano Pacífico favoreceram da mesma forma a elaboração de outros termos, como o cunhado em Liu et al. (2002) e Minobe (2000) para denominar a oscilação,cuja referência foi feita como Oscilação Bidecadal. Minobe (2000) sugeriu o nome Oscilação Pentadecadal. Esses autores discutiam a temporalidade da oscilação em períodos de 20 a 30 anos e de 50 a 70 anos.

Para Mantua e Hare (2002), os nomes como Oscilação Interdecadal do Pacífico, Oscilação do Pacífico Norte e Variação Decadal do Pacífico têm sido utilizados, mas a denominação Oscilação Decadal do Pacífico é a que indica a maturidade, desenvolvimento, ampliação da pesquisa e dos resultados de investigação do clima sobre a atividade pesqueira e os estudos de hidroclima.

No que tange à gênese da oscilação, Wu et al. (2003) sugerem que a oscilação se origina, predominantemente, a partir da interação oceanoatmosfera nos trópicos, em associação com um modo maior de ondas tropicais baroclínicas, com reforço extratropical-tropical substancial de interação via teleconexões oceânicas e atmosféricas (WU et al., 2003).

De outro modo, Newman et al. (2003), analisou a ODP segundo a variabilidade do ENOS. Para esses autores, a ODP seria o resultado do ENOS com temporalidade mais profunda. Em outras palavras, a ODP resume-se na observação do ENOS em sua variabilidade decadal, nesse sentido a oscilação

[...] is dependent upon ENSO on all timescales. To first order, the PDO can be considered the reddened response to both atmospheric noise and ENSO, resulting in more decadal variability than either. This null hypothesis needs to be considered when diagnosing and modeling "internal" decadal variability in the North Pacific. For example, the observed spatial pattern of Pacific SST decadal variability, with relatively higher amplitude in the extratropics than in the Tropics, should be at least partly a consequence of a reddened ENSO response (NEWMAN et al., 2003, p. 3856). ${ }^{3}$

\footnotetext{
${ }^{3}$ “[...] é dependente de ENOS em todos os prazos (escalas de tempo). Em primeiro lugar, a ODP pode ser considerada tanto uma resposta positiva, quanto um ruído atmosférico do ENOS, que resulta numa

R. Ra'e Ga - Curitiba, v. 35, p 314. - 343 , Dez/2015
} 
Mantua (1999) contesta a gênese da ODP associada ao padrão dos ENOS. Para esse autor, a oscilação apresenta estrutura e configurações similares ao ENOS quando estão em mesmas fases (ODP positiva e El Niño, ou ODP negativa e La Niña), mas se diferem quando configuradas em fases distintas (ODP negativa e El Niño, ou ODP positiva e La Niña), que apresentam sinais pouco discretos e marcados. Além disso, o autor qualifica a diferenciação de ODP e ENOS na escala temporal, na abrangência espacial e na estrutura climática.

Segundo esse autor, os ENOS possuem duração de 14 a 22 meses, são restritos à região do Pacífico Equatorial e possuem acoplagem oceano (TSMs) e atmosfera (Pressão). A ODP é basicamente observada por meio de TSMs, com temporalidade de 20 a 30 anos, e abrange tanto o Pacífico Tropical quanto o Extratropical (MANTUA, 1999).

Independentemente das interpretações explicativas para gênese da ODP, Kayano e Andreoli (2009) sugerem que a abordagem da sobreposição dos modos de variabilidade climática de baixa frequência (em escalas decadal e multidecadal, como a ODP), e os de modos de variabilidade de alta frequência (em escalas interanuais, como o ENOS) representam avanços bastante interessantes tanto na identificação de teleconexões climáticas (mais e menos frequentes aos modos), quanto na observação de alterações climáticas em algumas regiões do globo.

Segundo os autores, as fases ODP positiva favorecem maior ocorrência de EI Niños (fase quente do ENOS), enquanto que em ODP negativa, a tendência à ocorrência é maior para os La Niñas (fase fria do ENOS) (KAYANO e ANDREOLI, 2009). Os resultados encontrados por Oliveira et al. (2006), e Silva (2006), e Silva et al. (2011) corroboram essas afirmações.

variabilidade em periodicidade decadal de ambos. Essa hipótese anula a consideração da observação e da modelagem uma variação interna do Oceano Pacífico Norte, em escala decadal. Por exemplo, o padrão espacial observado pela variação em décadas das TSMs do Oceano Pacífico, com amplitude relativamente maior nos extratropicos do que nos trópicos, deve ser pelo menos em parte, a consequência de uma resposta ENOS positivo (NEWMAN et al., 2003, p. 3856, tradução nossa).

R. Ra'e Ga - Curitiba, v. 35, p 314. - 343 , Dez/2015 
Da mesma forma, sob a fase quente (fase fria) da ODP, a intensidade de episódios de El Niño (La Niña), se sobrepõe ao menor número e menor intensidade de La Niña (EI Niño), favorecendo sua ocorrência na forma de eventos seja curta ou rápida. (KAYANO e ANDREOLI, 2009). Essa configuração pode ser observada na Figura 4, por meio da variabilidade dos índices da ODP, segundo Mantua et al. (1997), e o Índice Multivariado do ENOS - MEI ${ }^{4}$.

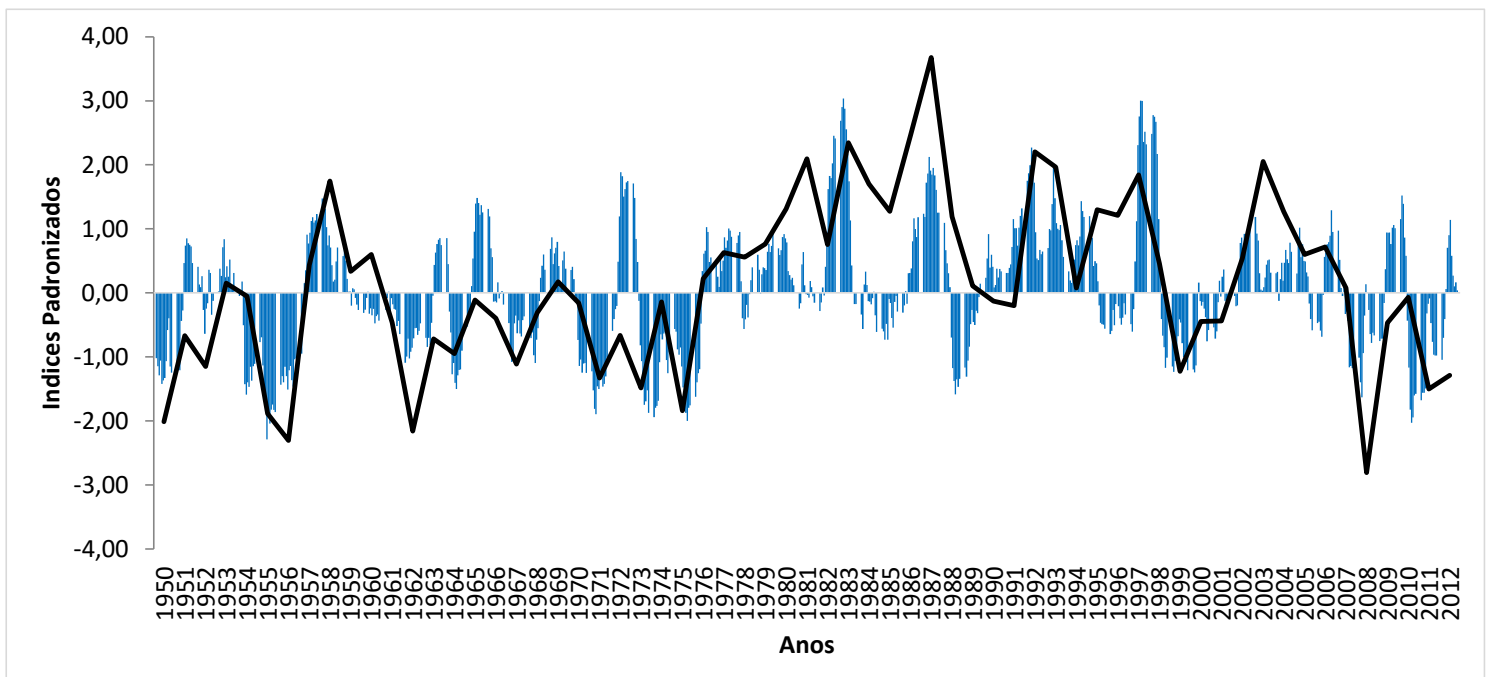

Figura 4 - Variabilidade mensal do Índice Multivariado do ENOS (barras na cor azul) e IODP anual (linha na cor preta). Fonte: NOAA (2013) e JISAO (2013).

Silva (2006), Cavalcanti e Ambrizzi (2009) e Kayano e Andreoli (2006; 2009) explicam esse aspecto como um background. Sugerem que quando 0 ENOS e ODP estão na mesma fase (fase oposta), um atua construtivamente (desconstrutivamente) contra o outro, mas não se eliminam.

As interferências climáticas foram observadas por Zhang et al. (1997), Silva (2006) e Garcia (2006). Esses autores detectaram que, sob ODP positiva,

\footnotetext{
${ }^{4} \mathrm{O}$ Índice Multivariado do ENOS ou Multivariate ENSO Index - MEI é um dos índices que representam o El Niño Oscilação Sul. O índice é gerado a partir do monitoramento de seis variáveis - pressão ao nível do mar e zonal, componentes meridionais do vento na superfície do mar, temperatura da superfície do mar, a temperatura do ar à superfície do mar, e fração totais de nebulosidade do céu observadas no Oceano Pacífico Tropical. O MEI é calculado separadamente para cada uma das doze temporadas bimestrais sequenciais e, depois, combinado e, por fim, há a filtragem espacial dos campos individuais em agrupamentos a partir da primeira componente principal de todas as variáveis (NOAA, 2012).
} 
os invernos tendem a ser mais quentes e favorecem o aparecimento de ar mais seco no noroeste do Pacífico, com menos precipitação e neve nas montanhas. As águas no Pacífico Tropical Leste e na estreita banda ao longo da costa do Alasca e do oeste dos Estados Unidos e do Canadá também tendem a ser mais aquecidas. O inverso ocorre quando configurada uma fase negativa da oscilação.

Do ponto de vista sinótico, o caráter da oscilação foi discutido por Garcia (2006) em termos de circulação atmosférica, na qual a ODP possui relação com a Célula de Walker e o Sistema de Monções da América do Sul (SMAS) ${ }^{5}$. Para a autora, a Célula de Walker pode se configurar com intensidades diferentes e com os seus centros ligeiramente deslocados nas fases negativa e positiva da oscilação. Verificou-se, também, que o SMAS varia em escala multidecadal - modo dominante do sistema, com padrões de anomalias similares aos da ODP.

Garcia (2006) destaca a grande consistência entre as variáveis sobre a América do Sul, já que: 1) na ODP- (ODP+) ocorrida antes (depois) de 1975, predomina o ar atmosférico mais frio (quente) em baixos níveis; 2) coincidem com essa configuração as anomalias de pressão no nível do mar positivas (negativas); 3) com movimento descendente (ascendente) anômalo em pares ciclônicos (anticiclônicos) simétricos em relação ao Equador à oeste da região; 4) anomalias negativas (positivas) de água precipitável e; 5) indica um enfraquecimento (fortalecimento) do SMAS na fase ODP- e ODP+. No Brasil, a distribuição espacial das anomalias de precipitação nos trimestres de JJA (junho, julho e agosto - parte superior da Figura 5) e DJF (dezembro, janeiro e fevereiro - parte inferior da Figura 5), pode auxiliar na visualização das alterações nos índices pluviométricas quando associados à temporalidade das fases da ODP.

\footnotetext{
${ }^{5}$ O SMAS é um sistema monçônico que apresenta com um ciclo anual de precipitação bem definido (seis meses secos e seis chuvosos), e explica $90 \%$ da precipitação na região central do Brasil, durante os meses mais quentes do ano (CAVALCANTI et al., 2006; GARCIA, 2006).
}

R. Ra'e Ga - Curitiba, v. 35, p 314. - 343 , Dez/2015 


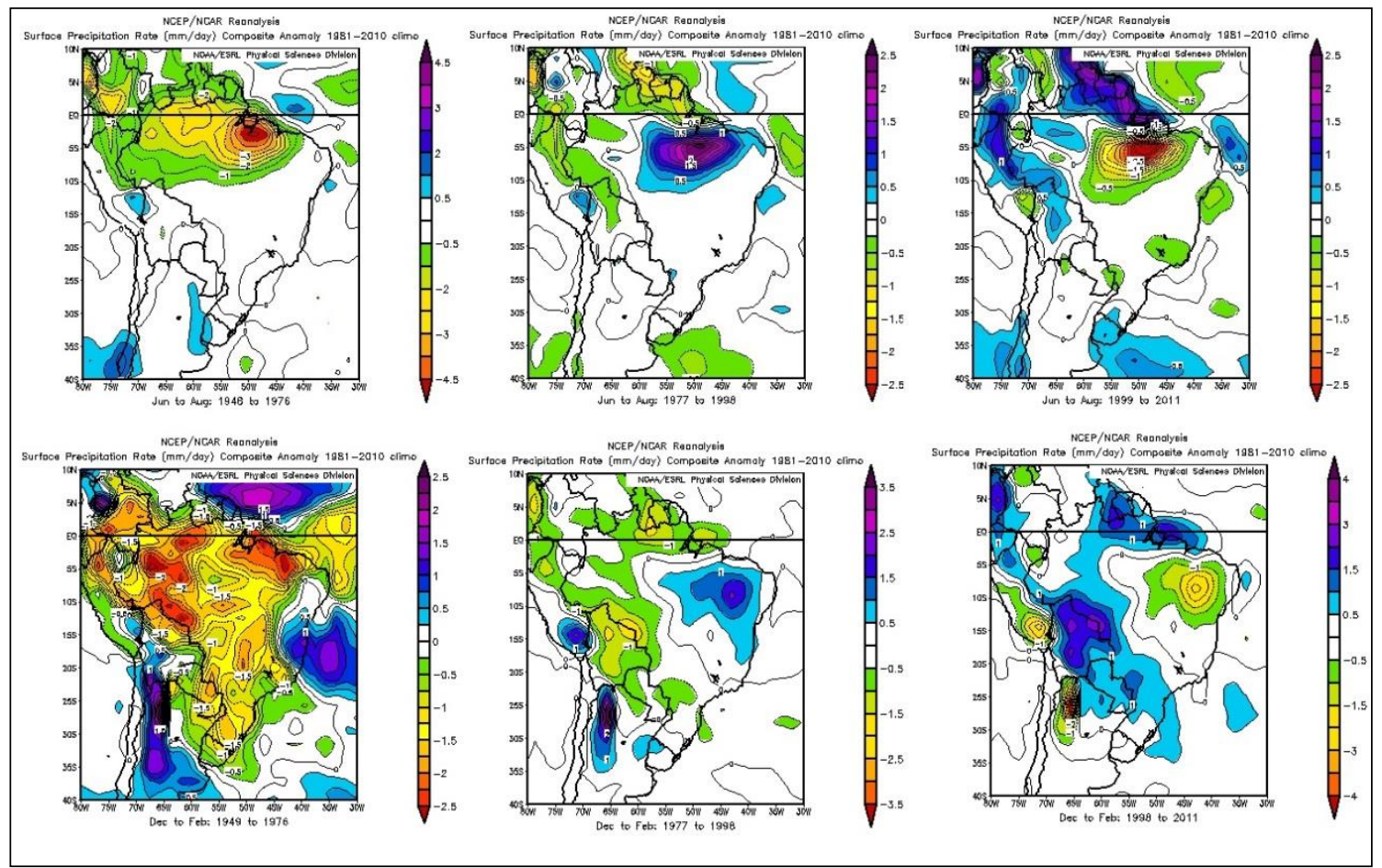

Figura 5 - Anomalia da precipitação média no Brasil nos trimestres de JJA (linha superior) e DJF (linha inferior) sob ODP- (1948 a 1976 - coluna da esquerda), ODP + (1977 a 1998 - coluna do meio) e ODP (1999 a 2011 - coluna da direita). Fonte: NOAA/ESRL Physical Sciences Division (NOAA, 2012). Org. Nascimento Jr e Sant'Anna Neto.

É possível observar que os valores não habituais no mesmo trimestre (anômalos) apresentam núcleos espaciais diferentes conforme as fases opostas da ODP. Nos trimestres apresentados (JJA e DJF), existe a tendência de diminuição de valores de precipitação em ocorrência da oscilação, principalmente em parte da Amazônia e do Nordeste Brasileiro. Essa configuração coincide com os resultados encontrados por Siqueira et al. (2006), Salvador et al. (2006), Silva (2006), Silva et al. (2011), e Xavier e Xavier (2009).

No Brasil, esses trimestres tendem a apresentar menores e maiores valores de precipitação sob ODP- e ODP+. Cabe destacar que a diferença temporal da ODP - de 1947 a 1976, para a sua fase fria mais recente (1998 a 2011) pode justificar de certa forma o padrão espacial desta última nos trimestres, devido ao desenvolvimento ainda que inicial.

\section{DADOS, TÉCNICAS, PROCEDIMENTOS E REPRESENTAÇÕES}

R. Ra'e Ga - Curitiba, v. 35, p 314. - 343 , Dez/2015 


\section{1 - A rede de postos e as séries temporais utilizadas}

Para essa análise foram utilizados dados mensais de Chuva Acumulada (mm) e Número de Dias com Chuva, da rede de postos pluviométricos do Instituto das Águas do Paraná - IAPAR (Figura 6).

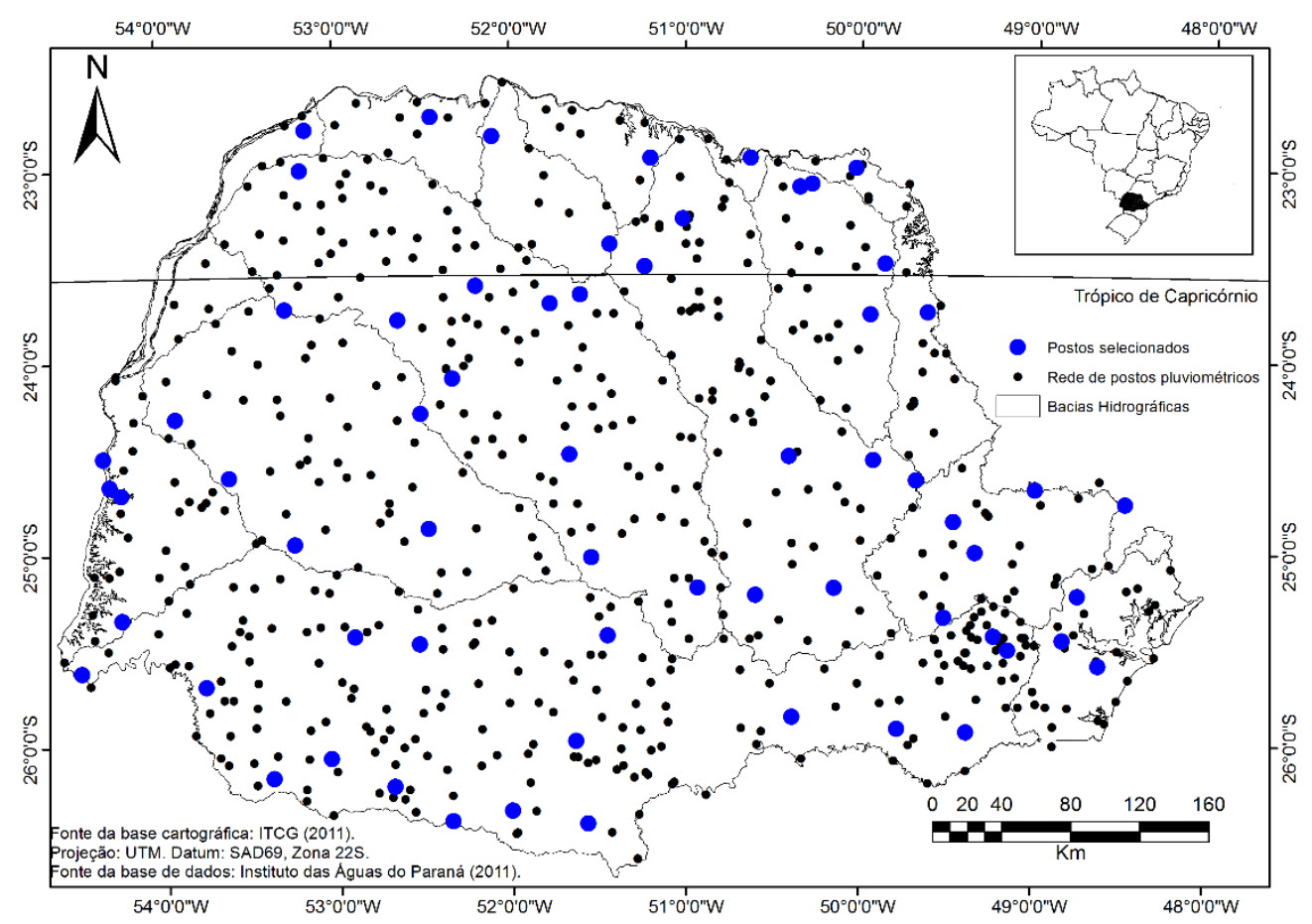

Figura 6 - Postos pluviométricos com série histórica de 1976 a 2011, a rede de postos pluviométricos e localização do Estado do Paraná no Brasil. Org. Nascimento Jr e Sant'Anna Neto.

A seleção dos postos pluviométricos foi processada priorizando a qualidade, a disponibilidade e a uniformidade dos dados na série histórica de 1976 a 2011. As associações com os padrões ODP foram representadas pelos índices mensais da (IODP), produzidos por Mantua et al. (1997) e Mantua e Hare (2002) e disponíveis em <http://jisao.washington.edu/pdo/PDO.latest>. Além dos índices, consideraram-se como base da ocorrência de suas fases os períodos de 1976 a 1998 como ODP+ e, de 1999 a 2011 a ocorrência da recente fase fria.

\subsection{Procedimentos e técnicas estatísticas}

A variabilidade trimestral foi representada pelos valores agrupados equivalentes aos trimestres de outono (março, abril e maio), inverno (junho, R. Ra'e Ga - Curitiba, v. 35, p 314. - 343 , Dez/2015 
julho e agosto), primavera (setembro, outubro e novembro) e verão (dezembro, janeiro fevereiro). A variabilidade sazonal foi representada por meio do agrupamento da estação mais úmida, denominada Estação Chuvosa (outubro a março) e Menos Chuvosa (abril a setembro). A variabilidade interanual foi representada pelos totais anuais padronizados.

Para obter a relação da ODP com a variabilidade pluviométrica, aplicouse a correlação linear, determinada pelo Coeficiente de Pearson. O coeficiente refere-se ao um procedimento numérico entre as variáveis, e não implica numa relação de causa e efeito, mas numa medida da intensidade de um relacionamento linear entre as duas variáveis.

Segundo Toledo e Ovale (2008), os valores de correlação $r$ variam entre 1 e -1 , sendo que o valor zero representa a ausência de correlação linear, conforme demonstrado a seguir:

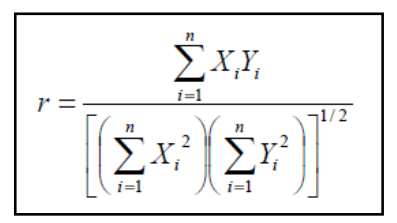

O teste foi aplicado considerando o nível de significância alfa $=0,05$. São representados os valores do quadrado do coeficiente de determinação $\left(r^{2}\right)$, que mostra o percentual da variância que explica a relação de uma das variáveis em relação à outra. Os valores de $r$ (coeficiente de correlação) foram utilizados para análise espacial.

\subsection{Procedimentos e técnicas estatísticas para análise espacial}

A análise espacial foi elaborada por meio da inserção dos resultados da correlação de Pearson num Sistema de Informações Geográficas, e por procedimentos geoestatísticos, conforme indicações de Landim (2012). Os resultados se referiram aos obtidos por posto pluviométrico, considerando a localização e os valores dos coeficientes de correlação entre as variáveis: IODP X Precipitação, e IODP X Número de Dias com Chuva.

Foi realizada análise variográfica dos valores para observação da correlação e continuidade espacial dos dados amostrais e, o sistema de 
equações utilizado foi o referente ao modelo teórico de interpolação Krigagem Ordinária (que considera a média flutuante ou móvel por toda a área a ser interpolada), inclusive nos casos de detecção de efeitos pepita ${ }^{6}$.

Os modelos foram ajustados considerando a variabilidade espacial dos valores na correlação significativa representada no semivariograma omnidirecional, sem anisotropia.

Os valores foram interpolados no software ArcGis $9.3^{\circledR}$, e todos os cálculos foram produzidos e realizados no software Microsoft Exce ${ }^{\circledR}$, no aplicativo XLStat ${ }^{\circledR}$.

\section{RESULTADOS, DISCUSSÃO E CONTRIBUIÇÕES}

Considerando as escalas temporais e os resultados obtidos por cada posto, é possível afirmar que a ODP é um dos moduladores da precipitação na primavera, no outono e na escala anual, respectivamente. Para os números de dias de chuva, a ODP sugere maior relacionamento no outono e na escala anual, respectivamente.

Quando submetido às correlações lineares (Tabela 1), os coeficientes que apresentam significância estatística determinam que, na precipitação, os valores de r $^{2}(\%)$ não passaram de 19,7\%. Os coeficientes da correlação entre os IODP e número de dias com chuva mostraram-se expressivos, principalmente na primavera.

Para a precipitação, os maiores valores de $r^{2}$ foram observados em Laranjal (setor centro-sul do Estado), no outono e na escala anual, com uma correlação positiva. O menor valor de $r^{2}(\%)$ foi notado em Marechal Cândido Rondon (11,1\%) (setor oeste), com correlações positivas. Correlações negativas foram constatadas na primavera de Paranaguá (setor litoral), no

\footnotetext{
${ }^{6}$ Segundo Landim (2012) o efeito pepita ou nugget effect é um valor que mostra descontinuidade do semivariograma para distâncias menores do que a menor distância entre as amostras. $O$ valor representa parte dessa descontinuidade que pode ser devida a erros de medição ou da variabilidade a uma escala menor do que aquela amostrada. Neste trabalho, os efeitos pepita detectados foram associadas à correspondência dos valores em escala local, cuja a variabilidade dos elementos é condicionada por fatores climáticos específicos.
} 
inverno de Prudentópolis (setor centro-sul) e no outono de Londrina (setor norte).

Tabela 1 - Coeficientes de determinação $\left(r^{2}\right)$ de Pearson para Precipitação e Número de dias com Chuva x IODP.

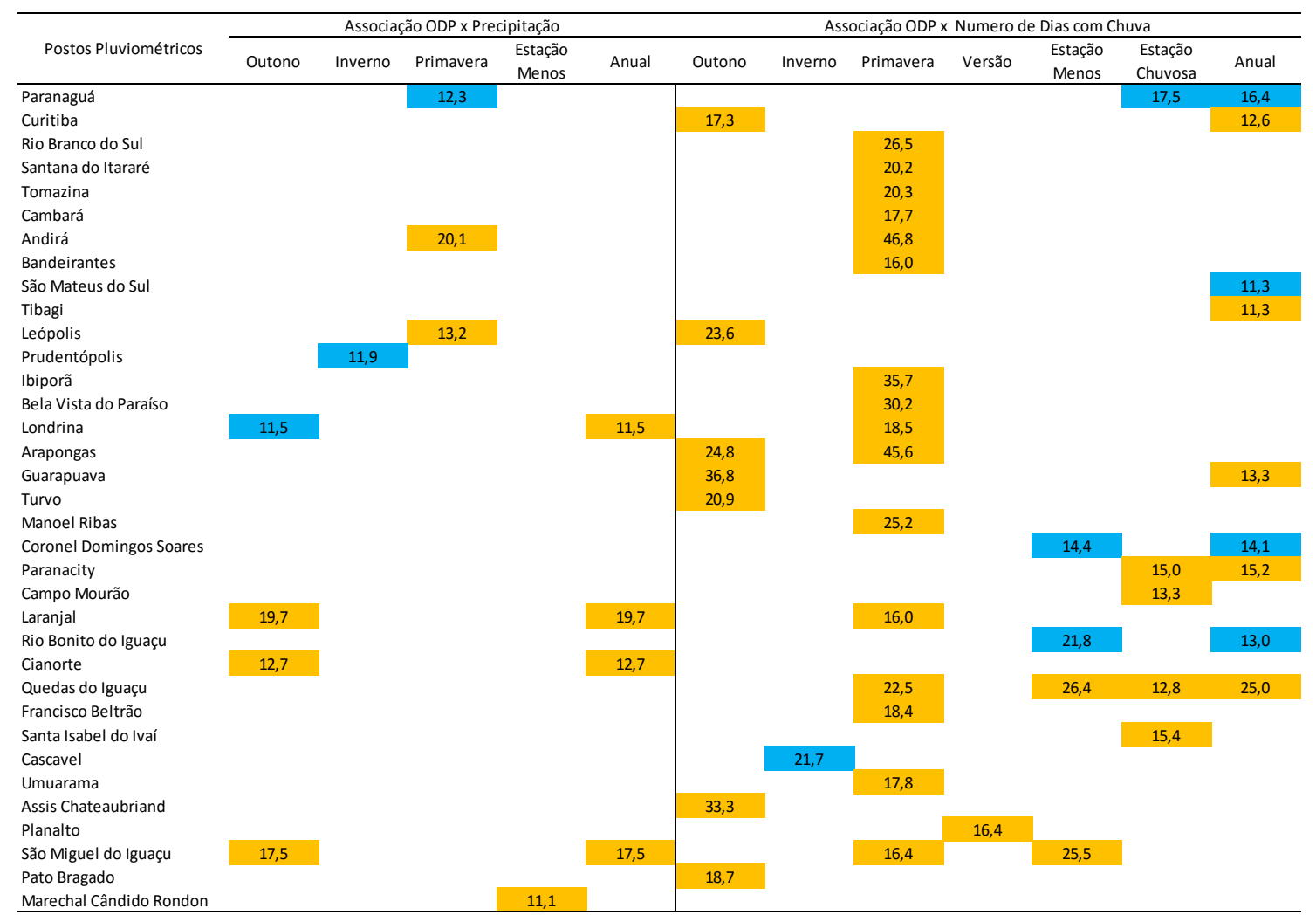

Inserido somente os valores diferentes de 0 , com um nível de significância alfa $=0,05$. Destaque para os valores de $r^{2}(\%)$ de correlação negativa (cor azul) e positiva (cor laranja). Org. Nascimento Jr (2013).

Nos números de dias com chuva, os coeficientes de determinação da correlação foram observados em todas as escalas. E o grau de participação da ODP se apresenta na faixa entre 11,3\% (em São Matheus do Sul - setor sul, e Tibagi - setor centro-leste) a 46,8\% (em Andirá - norte do Estado), com majoritariamente correlações positivas.

De outro modo, os coeficientes, quando espacializados, oferecem mais um parâmetro de observação da influência e das alterações espaciais da ODP na precipitação no Estado.

Cabe destacar primeiramente que: 
a) a participação da componente ODP nesse processo é fraca (para chuva acumulada), e moderada (para o número de dias com chuva) conforme observado na Tabela 2;

b) quando os coeficientes são positivos as correlações lineares mostraram padrão proporcional - isto é, quando a ODP é quente, os índices de chuva e número de dias de chuva tendem a ser positivos; ou quando a ODP está na fase fria, as precipitações e números de dias chuva são negativos;

c) quando as correlações são negativas, apresentam padrões inversamente proporcionais - ou seja, quando a ODP é quente ou está na fase quente, os índices de chuva e número de dias de chuva tendem a ser negativos; ou quando a ODP está na fase fria, as precipitações e números de dias de chuva são da mesma forma positivos; e,

d) são destacados somente os postos pluviométricos que apresentaram valor $\alpha \leq 0,05$, diferindo-se estatisticamente e significativamente.

Nesse sentido, a correlação entre IODP e Chuva no Paraná pode ser observado no trimestre de outono (Figura 7a e 7b). As correlações negativas (inversamente proporcionais) foram detectadas para as precipitações no leste, e para o número de dias de chuva foram observados em parte do sudoeste e no litoral. Enquanto que as positivas se configuraram nos setores continentais oeste.

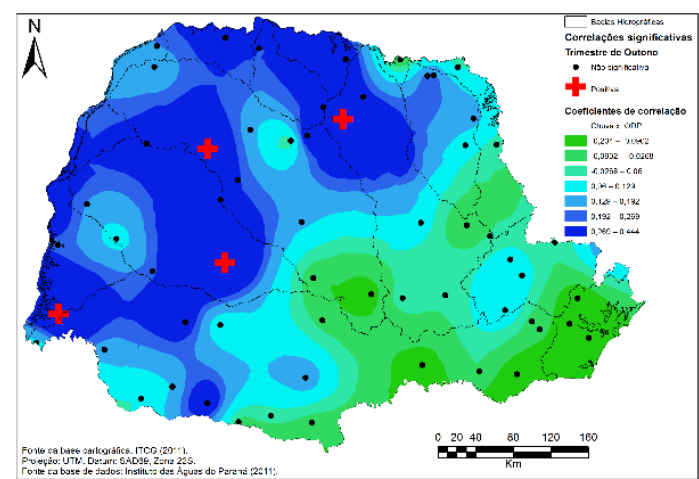

Figura 7a - Coeficientes de correlação entre Chuva x IODP para

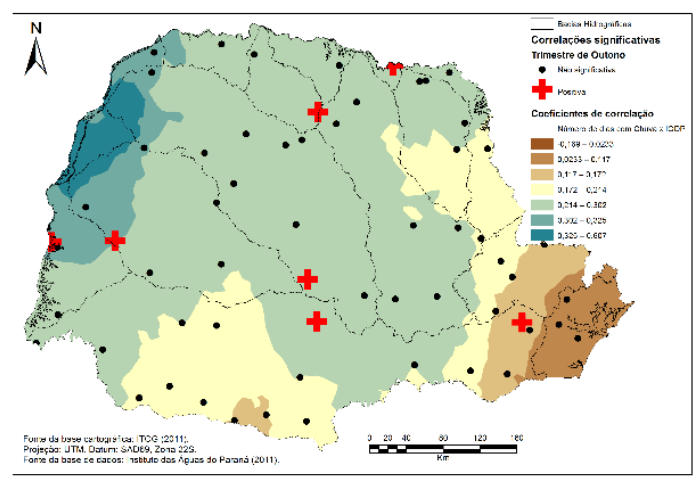

Figura 7b - Coeficientes de correlação entre Número de dias com chuva $x$

R. Ra'e Ga - Curitiba, v. 35, p 314. - 343 , Dez/2015 
CONTRIBUIÇÃO AOS ESTUDOS DA PRECIPITAÇÃO NO ESTADO DO PARANÁ: A OSCILAÇÃO DECADAL DO PACÍFICO - ODP
o Outono
IODP para o Outono

As correlações obtidas entre os valores do trimestre de inverno e os IODPs são negativos em grande parte do centro do Estado, marcando espacialmente todo o setor setentrional, enquanto que correlações positivas foram detectadas no sudoeste (Figura 8a).

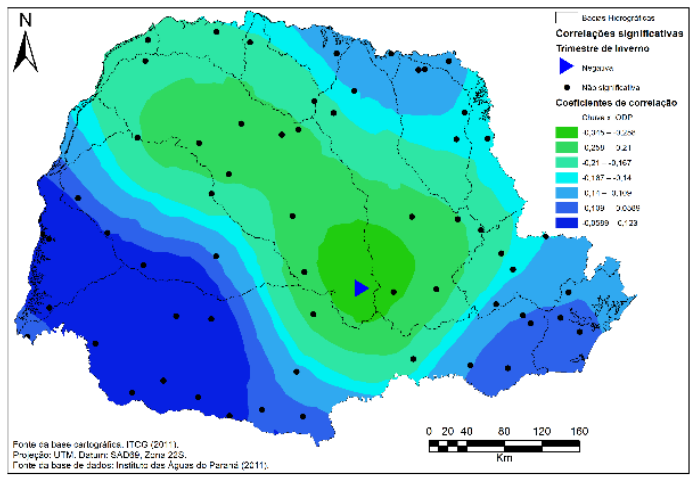

Figura 8a - Coeficientes de correlação entre Chuva x IODP para o Inverno

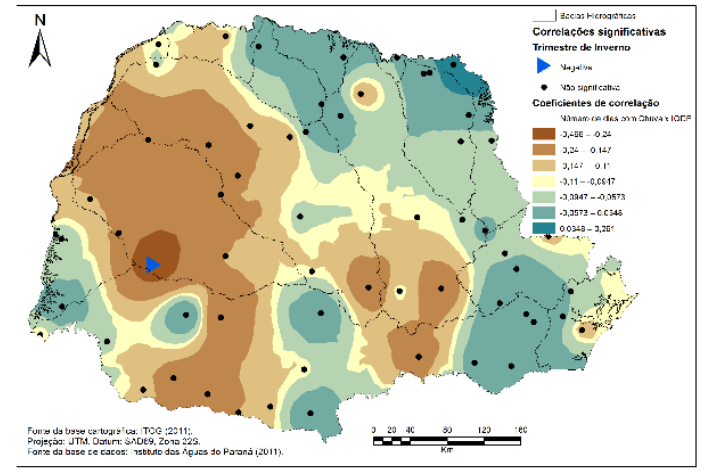

Figura 8a - Coeficientes de correlação entre Número de dias com Chuva x IODP para o Inverno

Efeitos pepita foram bastante expressivos para as correlações dos números dias de chuva no inverno (Figura 8b). Esse caráter favorece a interpretação de que, nesse trimestre, a ocorrência de número de dias de chuva é bastante expressiva e tem baixa relação espacial, inferindo-se sua produção em escala local. Por isso, as correlações (negativas e positivas) com IODP se apresentam numa feição difusa, apesar da relevância na região continental leste do Estado. Essa característica também foi detectada em outros trimestres e estações, conforme os próximos subsequentes.

No trimestre de primavera, tanto para chuva (Figura 9a) quanto para número de dias com chuva (Figura 9b), os coeficientes de correlação são contínuos e marcam valores positivos no setor norte, e negativos em parte do setor sul e leste. 


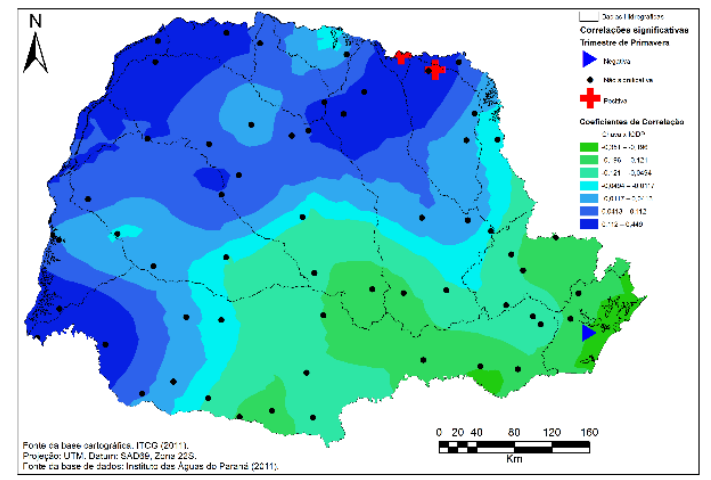

Figura 9a - Coeficientes de correlação entre Chuva x IODP para a Primavera

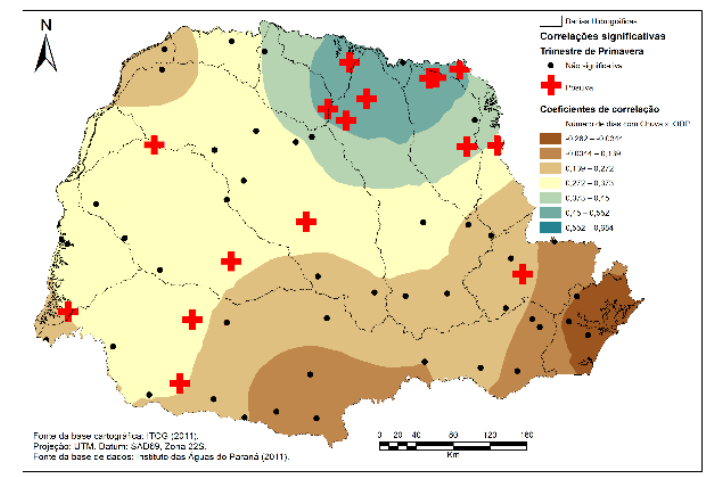

Figura $9 \mathrm{~b}$ - Coeficientes de correlação entre Numero de dias com

Chuva x IODP para a Primavera

No trimestre de verão (Figura 10a e 10b), apesar da relevância dos efeitos-pepita, as correlações para chuva acumulada estão distribuídas pelo Estado, com aparente homogeneidade nas áreas do litoral norte, em direção latitudinal ao centro do Estado, sob a bacia do Ivaí e no sudeste.

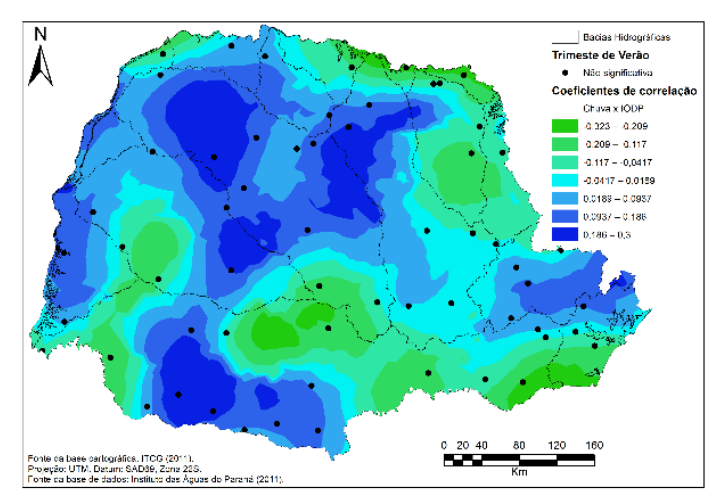

Figura 10a - Coeficientes de correlação entre Chuva x IODP para o Verão

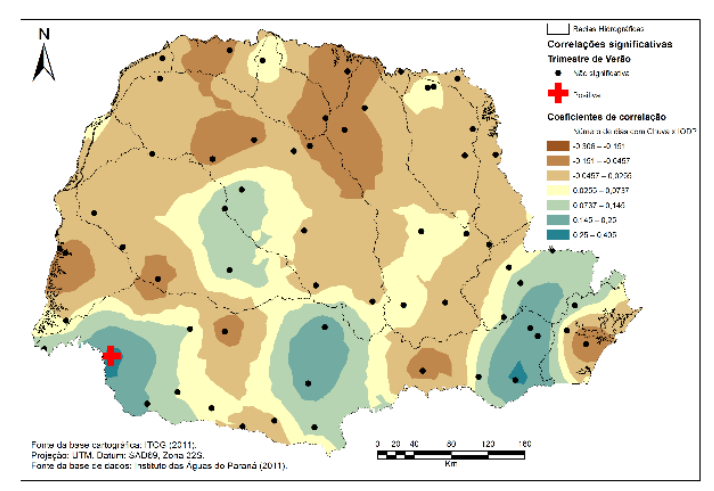

Figura 10b - Coeficientes de correlação entre Número de dias com Chuva x IODP para o Verão

Os coeficientes para o número de dias de chuva nesse trimestre (Figura 10b), também apresentaram efeito-pepita no processo de interpolação, e foram bastante dominantes no setor norte, com alguns sinais de correlação positiva no setor sul e no Primeiro Planalto.

As correlações positivas para precipitação $\times$ ODP dos valores sazonais equivalentes à Estação Menos Chuvosa (Figura 11a) foram detectadas por parte nordeste até o sudoeste do Estado. 


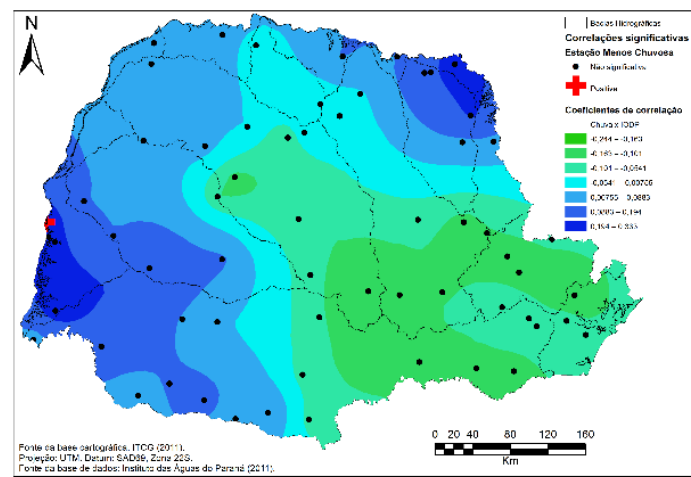

Figura 11a - Coeficientes de correlação entre Chuva x IODP na Estação Menos Chuvosa

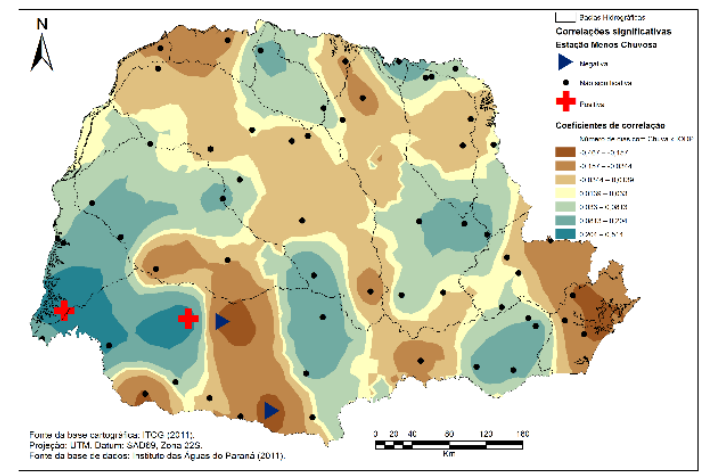

Figura 11b - Coeficientes de correlação entre Número de Dias com Chuva x IODP na Estação Menos Chuvosa

Do litoral até grande parte dos setores centrais, as correlações foram negativas. Nessa escala, o processo de interpolação também apresentou expressivos efeitos-pepita para as correlações entre número de dias de chuva e ODP, se apresentando de forma bastante difusa em todo território paranaense, principalmente para o número de dias com chuva (Figura 11b).

$\mathrm{Na}$ Estação Chuvosa, os valores negativos da correlação para as chuvas foram dominantes em grande parte da região leste (que compõe o litoral), e se estendeu até as regiões centrais, enquanto que valores positivos estão marcadamente concentrados no noroeste do Estado (Figura 12a). Os efeitos pepita também foram detectados na interpolação dos coeficientes de correlação entre número de dias de chuva e ODP (Figura 12b).

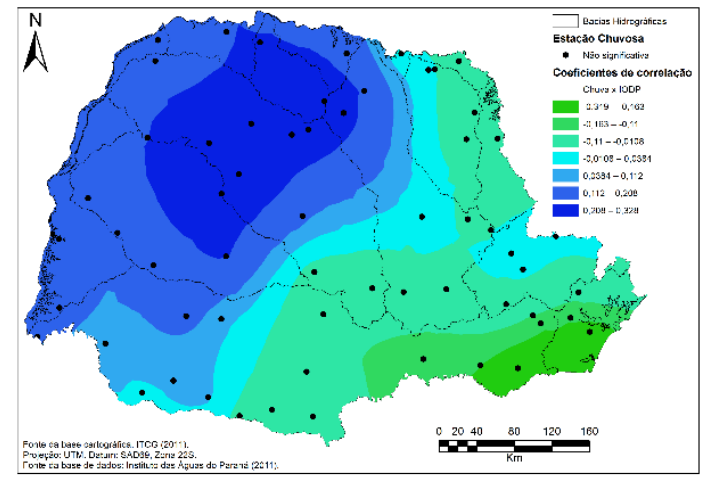

Figura $12 \mathrm{a}$ - Coeficientes de correlação entre Chuva x IODP na Estação Chuvosa

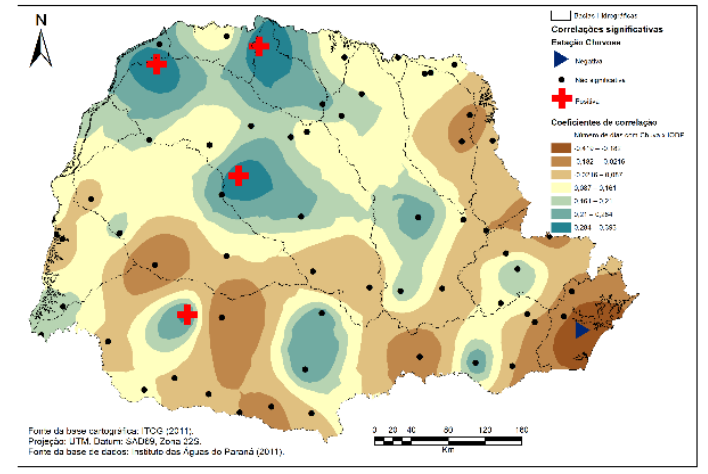

Figura 12b - Coeficientes de correlação entre Número de dias com chuva x IODP na Estação Chuvosa 
$\mathrm{Na}$ escala anual, correlações negativas para os valores de chuva, também foram predominantes no leste do Estado, enquanto as positivas ocorreram no noroeste (Figura 13a). As correlações positivas para o número de dias com chuva também apresentam efeito-pepita e foram predominantes no norte do Estado (Figura 13b).

Com base nos resultados observados nas séries temporais espacialmente distribuídas pelo território paranaense, é possível afirmar que a ODP é um dos moduladores decadais na primavera, no outono e na escala anual para os NDC. Para o total de precipitação, a ODP aparece como um modulador decadal no outono e na escala anual.

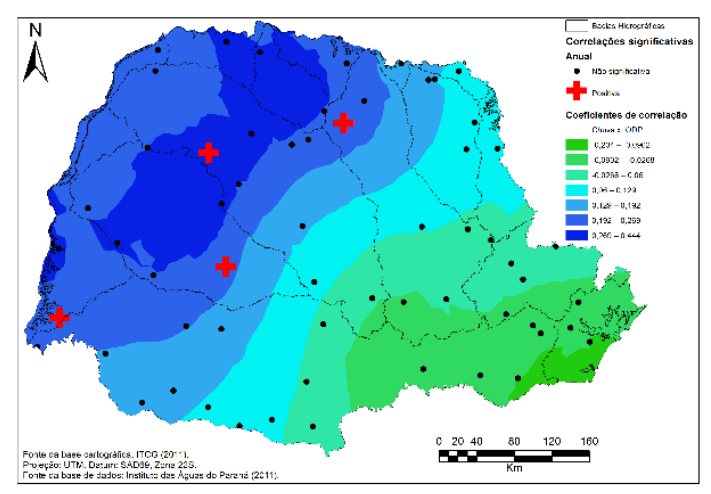

Figura 13a - Coeficientes de correlação entre Chuva x IODP na escala Anual

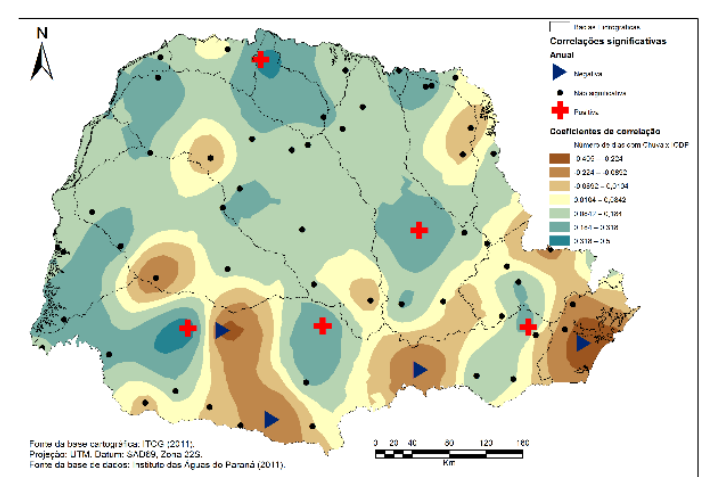

Figura 13b - Coeficientes de correlação entre Número de dias com chuva x IODP na escala Anual

Em geral, os maiores valores dos coeficientes de correlação, bem como os valores estatisticamente significativos são observados majoritariamente no oeste e noroeste do Estado. Em todos os períodos as configurações corroboram com as considerações de Garcia (2006), sobre o deslocamento e a intensidade da SMAS.

\section{CONSIDERAÇÕES FINAIS}

Conclui-se que a participação da ODP na variabilidade espaço temporal das chuvas no Paraná é estatisticamente considerada fraca para os totais de chuva e moderada-fraca para os números de dias com chuva. 
Os valores da correlação ficaram entre $11 \%$ a $20 \%$ para os totais anuais de chuva e se apresentaram com maior significância estatística nos trimestres de outono e primavera. Para os números de dias de chuva, a correlação foi de $17 \%$ a $46 \%$, e se deu principalmente no trimestre da primavera.

$\mathrm{Na}$ análise espacial, os coeficientes de correlação das chuvas acumuladas e IODP apresentaram distribuição regional contínua. Diferentemente, os números de dias com chuva, expressaram resultados muito associados à escala local. Essa característica foi detectada pelos resultados do processo de interpolação que apresentaram relevantes efeitos pepita.

Essa característica mostra que os valores de precipitação e número de dias de chuva possuem estruturas diferentes, com sinais de associação quase distintos aos mecanismos de escalas globais e regionais, como a ODP. Os totais de dias com chuva são essencialmente locais, mas se associam em grande parte à atuação de teleconexões. Por outro lado, as chuvas que também podem ser locais, apresentam condicionantes muito associados aos mecanismos climáticos em escala regional.

Nesse sentido, correlações positivas foram detectadas principalmente nas regiões oeste e noroeste, enquanto as negativas foram especializadas no setor leste e no litoral do Estado. Essa configuração explica parte do papel da ODP na distribuição espacial das chuvas, mediante as alterações que provoca no deslocamento espacial e na intensidade do modo dominante do Sistema de Monções da América do Sul e no favorecimento da entrada de sistemas atmosféricos com gênese no Oceano Atlântico.

Novos trabalhos devem ser empreendidos com vias a estabelecer melhor conhecimento sobre a participação da ODP na precipitação e no clima do Estado do Paraná. Eles podem ser orientados tanto para utilização de outras técnicas estatísticas (análise de componentes principais, correlações múltiplas, ondaletas, etc.), como também associações com a dinâmica climática, utilizando a relação com fenômenos regionais e zonais (El niño, Oscilação Sul, Dipolo do Atlântico) e a frequência e intensidade de sistemas atmosféricos produtores de tempo e clima (zonas de convergência do atlântico 
sul, frentes quentes e polares, sistemas convectivos de mesoescala, massas de ar, etc.).

No geral, os resultados corroboram para o melhor entendimento da gênese das chuvas para o mundo tropical e subtropical e, para o Estado do Paraná em particular, atestando também para os estudos sobre os impactos regionais e locais das mudanças climáticas e a influência das teleconexões de baixa frequência em sua variabilidade.

\section{AGRADECIMENTOS}

À Fundação de Amparo à Pesquisa do Estado de São Paulo - FAPESP, pelo financiamento (Processo: 2011/03089-7 e 2012/05301-6). Ao Grupo de Pesquisa GAIA - Interações na superfície, água e atmosfera da UNESP/Presidente Prudente pela infraestrutura e ambiente agradável. Aos geógrafos Vinicius Carmello e Nubia Beray Armond pelas contribuições e leitura.

\section{REFERÊNCIAS BIBLIOGRÁFICAS}

BALDO, M. C. Variabilidade pluviométrica e a dinâmica atmosférica na bacia hidrográfica do Rio Ivaí - PR. Tese de Doutorado. Presidente Prudente. 2006.

BEAMISH, R. J; BOUILLON, D.R. Pacific salmon production trends in relation to climate. Canadian Journal of Fisheries and Aquatic Sciences, 50, 1993, p. 1002-1016.

REBELLO, E. R. G.; A Oscilação Decadal do Pacífico e sua possível influência no clima do sul do Brasil, 23.03.2005, INMET, Brasília - DF, 2005.

CAVALCANTI; I, F, A; AMBRIZZI, T. Teleconexões e suas influencias no Brasil. In: CAVALCANTI, I, F. A; FERREIRA, N. J; SILVA, M, G, A, J; DIAS, M. A. F. S (Orgs). Tempo e clima no Brasil. Oficina de Textos. 2009, p. 318-335

; OLIVEIRA, G. S. de. Teleconexões. Climanálise. Centro de Previsão e Tempo e Estudos Climáticos (CPTEC/INPE). Ed. espacial. Comemoração de 10 anos. 1996.

; CAMILLONI, L; AMBRIZZI, T. Escenarios climaticos regionales. In: BARROS, V; CLARKE, R; SILVA DIAS, P. EI Cambio climático en la cuenca del Plata. Buenos Aires, CIMA/CONICET. 2006, p. 175-190. 
FREITAS, E. D. Variabilidade sazonal e intrasazonal da precipitação no Estado do Paraná. Dissertação de Mestrado. Departamento de Ciências Atmosféricas, IAG/USP, 1998. 133p

GARCIA, S. R. Variabilidade do Sistema de Monção da América do Sul: relações com a Oscilação Decadal do Pacífico. 2006. Dissertação (Mestrado em Meteorologia). CPTEC/ INPE. São José dos Campos. 142 p.

GRIMM, A. M. Clima da região Sul do Brasil. In: CAVALCANTI, I, F. A; FERREIRA, N. J; SILVA, M, G, A, J; DIAS, M. A. F. S (Orgs). Tempo e clima no Brasil. Oficina de Textos. 2009a, p. $260-275$.

Variabilidade interanual do clima do Brasil. In: CAVALCANTI, I, F. A; FERREIRA, N. J; SILVA, M, G, A, J; DIAS, M. A. F. S (Orgs). Tempo e clima no Brasil. Oficina de Textos. 2009b, p. $260-275$.

How do La-Niña events disturb the summer monsoon system in Brazil? Climate Dynamics, v. 22, n. 2-3, mar/2004, p. 123-138.

; GUETTER, A. K; CARAMORI, P. H. El Niño no Paraná: o que pode esperar em cada região - uma análise científica. Informativo. Curitiba, n.1, 1997.

HARE. R; FRANCIS, R.C. Climate Change and Salmon Production in the Northeast Pacific Ocean. In: Canadian Special Publication of Fisheries and Aquatic Sciences, 1995, p. 121 - 147.

IAPAR. Instituto Agronômico do Paraná. Cartas climáticas do Paraná. CAVIGLIONE, J. H; KIIHL, L. R. B; CARAMORI, P. H; OLIVEIRA, D. Londrina: IAPAR, 2000.

INSTITUTO DAS ÁGUAS DO PARANÁ. Águas Paraná. Dados de postos pluviométricos. 2011.

ITCG. Instituto de Terras, Cartografia e Geociências. Secretaria do Meio Ambiente e Recursos Hídricos. Produtos cartográficos. Disponível em: http://www.itcg.pr.gov.br/modules/conteudo/conteudo.php?conteudo=47.

JISAO. Joint Institute for the Study of the Atmosphere and Ocean. The Pacific Decadal Oscillation (PDO) Index. 2012. Disponível em: http://research.jisao.washington.edu/pdo/PDO.latest. Acesso: 20 mai. 2012.

KAYANO, M. T. ANDREOLI, R. V. Relations of South American summer rainfall interannual variations with the Pacific Decadal Oscillation. In: Journal of Climate, v. 27, 4, 2006, p. $531-540$. 
Variabilidade decenal e multidecadal. In: CAVALCANTI, I, F. A; FERREIRA, N. J; SILVA, M, G, A, J; DIAS, M. A. F. S (Orgs). Tempo e clima no Brasil. Oficina de Textos. 2009, p. $375-381$.

LANDIN, P. M. B. Análise Estatística de Variáveis Regionalizadas. Material didático apresentado em aula. Rio Claro. 2012

LIU, Z.; WU, L; GALLIMORE, R; JACOBS, R. Search for the origins of Pacific Decadal Climate Variability. Geophysical Research Letters , v. 29, n. 10, art. no 1404, may. 2002.

MAACK, R. Geografia física do Estado do Paraná. José Olympio. Rio de Janeiro, 1981, p. 155-177.

MANTUA, N.; The Pacific Decadal Oscillation and Climate Forecasting for North America. To appear in premiere issue of "Climate Risk Solutions" newsletter. $1999 . \quad$ Disponível em: http://www.atmos.washington.edu/ mantua/REPORTS/PDO/PDO_cs.htm.

Aceso: 20 abr. 2011.

; HARE, S. R Pacific Decadal Oscillation. Journal of Oceanography, v. 58, n. 1, fev, 2002. p. 1069-1079.

MANTUA, N. J; HARE, S. R.; ZHANG, Y.; W, J. M.; FRANCIS, R. C. A Pacific Interdecadal Climate Oscillation with Impacts on Salmon Production, Bulletin of the American Meteorological Society, Vol. 78, 1997, p. 10691079.

MENDONÇA, F; Tipologia climática - Gênese, características e tendência. STIPP, N. A. F. (Org) Macrozoneamento da bacia hidrográfica do rio Tibagi/PR. Londrina: Editora UEL, 2000.

; DANNI-OLIVEIRA, I. M.; Climatologia: noções básicas e climas do Brasil. São Paulo. Oficina de texto. 2007.

MINOBE, S. Spatio-temporal structure of the pentadecadal variability over the North Pacific. Progress in Oceanography, v. 47, n. 2-4, p. 381-408, oct. 2000.

MOLION, L C. B. Aquecimento Global, El Niños, Manchas Solares, Vulcões e Oscilação Decadal do Pacífico. São José dos Campos CPTEC/INPE. In: Climanálise, ano 3, n. 1, p 1 - 5. Ago/2005.

MONTEIRO, C. A. F. Clima. In: Instituto Brasileiro de Geografia E Estatística (Ed.). Geografia do Brasil: Grande Região Sul. Rio de Janeiro, v.4, n.18, Tomo I, p.114-166, 1968. 
CONTRIBUIÇÃO AOS ESTUDOS DA PRECIPITAÇÃO NO ESTADO DO PARANÁ: A OSCILAÇÃO DECADAL DO PACÍFICO - ODP

NASCIMENTO JÚNIOR, L. As chuvas no Paraná: variabilidade, teleconexões e impactos de eventos extremos. Mestrado em Geografia. Universidade Estadual Paulista. Presidente Prudente, 2013. 162 p.

; Aspectos observacionais das teleconexões climáticas no contexto da variabilidade. Observatorium: Revista Eletrônica de Geografia, v.6, n.16, mai. 2014, p. 46-58.

NERY, J. T.; VARGAS, W.M.; MARTINS, M.L.O. Caracterização da precipitação no Estado do Paraná. Revista Brasileira de Agrometeorologia, Santa Maria, v. 4, n. 2, p. 81-89, 1996.

Variabilidade interanual da precipitação do Paraná. Revista Brasileira de Agrometeorologia. Santa Maria, v.5, n.1, 1997, p.115-125.

NEWMAN, M, COMPO, G.P, ALEXANDER, M.A. ENSO-Forced variability of the Pacific Decadal Oscillation. Journal of Climate. Vol. 16, $n^{\circ} 23$, December, 2003 (3853-3857).

NIMER, E. Climatologia do Brasil. Instituto Brasileiro de Geografia e Estatística, Rio de Janeiro, 1989.

NOAA. National Oceanic Atmosferic Administration. National Weather Service. Climate Precdtion Center. Teleconnections. Disponível em: http://www.cpc.ncep.noaa.gov/products/precip/CWlink/daily_ao_index/teleconn ections.shtml. Acesso: 20 jan. 2013

(PDO). National Climatic Data Center. Pacific Decadal Oscillation
Disponível http://www.nwfsc.noaa.gov/research/divisions/fed/oeip/ca-pdo.cfm. Acesso: 20 jan. 2013.

Physical Sciences Division. Linear Correlations in Atmospheric Seasonal/Monthly Averages. Disponível em: http://www.esrl.noaa.gov/psd/data/correlation/. Acesso: 20 maio 2012.

NOGAROLLI, M. Evolução climática do Estado do Paraná: 1970 1999. 2007. Dissertação (Mestrado em Geografia). Universidade Federal do Paraná. Curitiba.

$\begin{array}{lll}\text { Anais...GeoSimpósio. Estado do Paraná - tem um novo clima? } & \text { Disponível }\end{array}$ http://www.nilsonfraga.com.br/anais/NOGAROLLI_Mozart.pdf. Acesso: 30 abr. 2010.

PARIZOTTO, T. M. NERY, J. T. Associação da precipitação pluvial e anomalia da superfície do mar no oceano pacífico equatorial, na bacia do

R. Ra'e Ga - Curitiba, v. 35, p 314. - 343 , Dez/2015 
Paranapanema. Anais do $8^{\circ}$ Simpósio Brasileiro de Climatologia Geográfica. Alto Caparaó. 2008, p. 221 -223.

PEREIRA, L. M. P; CARAMORI, P. H; RICCE, W, S; SILVA, D. A. B; CAVIGLIONE, J. H. Determinação do início e término da estação chuvosa no Estado do Paraná. In: Geografar. Curitiba; v.3, n.2. Jul/dez. 2008, p. 1-12.

ROSEGHINI, W. F. F; NERY, J. T; MARTINS, M. de L. O. Variabilidade sazonal da precipitação na região noroeste do Paraná. Anais...Congresso Brasileiro de Meteorologia. Disponível em: http://www.cbmet.com/cbm-files/12e0f4287a58776ab08a531225633b9531.pdf. Acesso: 05 ago. 2010.

SMITH, L. I. A tutorial on Principal Components Analysis. Disponível em: www.cs.otago.ac.nz/cosc453/student_tutorials/principal_components.pdf>. 2002. Acesso: 12 jun. 2011.

SILVA, G. A. M. da; DRUMOND, A.; AMBRIZZI, T. The impact of EI Niño on South American summer climate during different phases of the Pacific Decadal Oscillation. Theoretical and Applied Climatology, v. 36, p. 100-120, 2011.

SILVA, L. F. Precipitação do norte do Nordeste Brasileiro e padrões de temperatura da superfície e pressão ao nível do mar: relações com as fases do El Niño/Oscilação Sul e Oscilação Decadal do Pacífico. 2006. Dissertação (Mestrado em Meteorologia). CPTEC/INPE. São José dos Campos.

SOUZA, P. Estudo da variabilidade da precipitação no Estado do Paraná associado à anomalia da TSM no Oceano Pacífico. Dissertação de Mestrado. Universidade Estadual de Maringá. Maringá, 2006.

TOLEDO, G. L; OVALLE, I. J. Estatística Básica. 2. Ed. São Paulo: Atlas, 1985.

TROPPMAIR, H. Perfil fitoecológico do Estado do Paraná. Boletim de Geografia. Maringá. UEM, v. 8, n. 1. 1990, p. 67-81.

VANHONI, F; MENDONÇA. F. O clima do litoral do Estado do Paraná. Revista Brasileira de Climatologia, Vol. 3, 2008, p. 49 - 53.

WANG, B. Interdecadal changes in El Niño onset in the last four decades. Journal of Climate, n. 8, 1995, p. 267-285.

WANG, S.; ZHAO, Z.; CHEN Z.; Reconstruction of the summer rainfall regime for the last 500 years in China. GeoJournal, v. 5, n.2, p. 117-122, 1981. 
WU, L; LIU, Z; GALLIMORE, R;, JACOB, R.LEE, , D; ZHONG, Y., Pacific decadal variability: the Tropical Pacific Mode and the North Pacific Mode. Journal of Climate, 2003: 1101-1120.

XAVIER, T. M. B. S.; XAVIER, A. F. S. A ODP "Oscilação Decadal do Pacífico" ( PDO- Pacific Decadal Oscillation") e eventos no Atlantico Intertropical e no Nordeste Setentrional do Brasil. Anais... Congresso Brasileiro de Meteorologia. Disponível em: www.cbmet.com/cbm-files/22fd48270b9ca0df5c7442c4b5c6074751.doc. Acesso: 20 abr. 2009.

ZANDONADI, L. As chuvas na Bacia do Paraná: aspectos temporais, espaciais e rítmicos. 2006. Rio Claro. Dissertação (mestrado em geografia). 2006. $136 \mathrm{f}$.

ZHANG, Y.; WALLACE, J. M.; BATTIST, D. ENSO-like interdecadal variability: 1900-93. Journal of Climate, v. 10, n. 5, p. 1004-1020, May. 1997. 